\title{
Specific phosphorylation and activation of ERK1c by MEK1b: a unique route in the ERK cascade
}

\author{
Yoav D. Shaul, ${ }^{1}$ Gilad Gibor, ${ }^{1}$ Alexander Plotnikov, and Rony Seger ${ }^{2}$ \\ Department of Biological Regulation, Weizmann Institute of Science, Rehovot 76100, Israel
}

\begin{abstract}
Extracellular signal-regulated kinases (ERKs) are key signaling molecules that regulate a large number of cellular processes, including mitosis. We showed previously that ERK1c, an alternatively spliced form of ERK1, facilitates mitotic Golgi fragmentation without the involvement of ERK1 and ERK2. Here we demonstrate that activation of ERK1c is mainly mediated by mitogen-activated protein kinase (MAPK)/ERK kinase 1b (MEK1b), which is an alternatively spliced form of MEK1 that was previously considered an inactive kinase. MEK1b phosphorylation and activity are preferentially stimulated by nocodazole, to induce its specific activity toward ERK1c. MEK1/2, on the other hand, preferentially target ERK1/2 in response to growth factors, such as EGF. As previously demonstrated for ERK1c, also MEK1b expression and activity are elevated during mitosis, and thereby enhance Golgi fragmentation and mitotic rate. MEK1 activity is also increased during mitosis, but this isoform facilitates mitotic progression without affecting the Golgi architecture. These results illustrate that the ERK cascade is divided into two routes: the classic MEK1/2-ERK1/2 and the splice-variant MEK1b-ERK1c, each of which regulates distinct cellular processes and thus extends the cascade specificity.
\end{abstract}

[Keywords: MEK; ERK; signaling cascades; Golgi fragmentation; cell cycle]

Supplemental material is available at http://www.genesdev.org.

Received January 29, 2009; revised version accepted June 3, 2009.

The extracellular signal-regulated kinase (ERK) cascade is a central mitogen-activated protein kinase (MAPK) pathway, which is activated by a large variety of extracellular agents, including growth factors and hormones (Seger and Krebs 1995; Shaul and Seger 2007). Upon activation, this cascade plays a central role in the induction of cellular processes such as proliferation, differentiation, learning and memory, and development. Under certain conditions, the cascade also regulates cell survival, migration, apoptosis, morphology determination, oncogenic transformation, and more. The ERK cascade is often activated by the small GTPase Ras, which recruits the Ser/Thr kinases Raf- 1 and B-Raf to the plasma membrane leading to their activation (Wellbrock et al. 2004). Once activated, the Raf kinases transmit the signals to MAPK/ERK kinases 1 and 2 (MEK1/2), which are dual-specificity protein kinases specific to the ERK cascade (Shaul and Seger 2007). A-Raf, MOS, Tpl2, and MEKK1 are also activators of MEK1/2, but operate under distinct and unique conditions. Upon activation, MEKs phosphorylate ERK1 and ERK2 (ERK1/2), as well as ERK1b, and this phosphorylation results in the full activation of these kinases. The

${ }^{1}$ These authors contributed equally to this work.

${ }^{2}$ Corresponding author.

E-MAIL rony.seger@weizmann.ac.il; FAX 972-8-9344116.

Article is online at http://www.genesdev.org/cgi/doi/10.1101/gad.523909. active ERK1/2 phosphorylate a large number of regulatory proteins, including MAPKAPKs and transcription factors, which leads to regulation of the diverse cellular processes influenced by the ERK cascade.

The 45-kDa MEK1, 46-kDa MEK2, and 43-kDa MEK1b constitute an evolutionarily conserved group of highly homologous mammalian proteins (Bendetz-Nezer and Seger 2005). Structural analysis of MEK1/2 revealed that they contain a catalytic domain, which is similar to that of other protein kinases (Ohren et al. 2004). This domain is surrounded by an $\mathrm{N}$-terminal and shorter $\mathrm{C}$-terminal regions, which are regulatory domains. MEK1/2 are activated by their upstream regulators through phosphorylation on two Ser residues in their activation loop (Ser218 and Ser222) (Alessi et al. 1994). They are localized mostly in the cytoplasm (Jaaro et al. 1997), where they interact with ERK1/2 through their $\mathrm{N}$-terminal $\mathrm{D}$ domain, and thereby can induce cytoplasmic anchoring, as well as rapid activation of ERK1/2 upon stimulation (Tanoue et al. 2000). An alternative spliced isoform of MEK1, termed MEK1b, which lacks 26 amino acids within its kinase domain, was identified in humans (Seger et al. 1992; Zheng and Guan 1993). This isoform does not significantly activate ERK1/2 upon stimulation and, therefore, was suggested to be an inactive MEK isoform (Zheng and Guan 1993). 
In the next level of the cascade, ERK1/2 are two evolutionarily conserved homologous genes that encode two main proteins, 44-kDa ERK1 and 42-kDa ERK2 (Seger and Krebs 1995). Both are activated by phosphorylation of the regulatory Thr and Tyr residues in their activation loops. In resting cells, ERK1/2 are localized in the cytoplasm due to interaction with various anchoring proteins, including MEKs. This interaction is mainly mediated by a region in ERK1/2, termed cytosolic retention sequence (CRS)/common docking (CD) motif that also regulates ERK1/2 interaction with MEK1/2 and phosphatases. Upon activation, they dissociate from their cytoplasmic anchors and translocate into the nucleus (Shaul and Seger 2007). Aside from ERK1/2, several alternatively spliced forms of these proteins have been described, including the rodent ERK1b (Yung et al. 2000), the primate ERK1c (Aebersold et al. 2004), and ERK2b (Gonzalez et al. 1992). All these kinases are composed of a catalytic kinase domain wrapped by regulatory stretches, but also contain unique inserts that distinguish them from the main ERK1/2 proteins.

ERK1c is generated by the insertion of intron 7 into the coding region of primate ERK1. This insertion contains a stop codon, resulting in the expression of a $41-\mathrm{kDa}$ protein kinase that contains modified 18 amino acids, just C-terminal to the CRS/CD domain. We showed that this protein is regulated differently from ERK1/2 due to its altered regulatory $\mathrm{CRS} / \mathrm{CD}$ and $\mathrm{C}$-terminal regions (Aebersold et al. 2004). Moreover, we established that during mitosis and elevations in cell density, ERK1c relocates to the Golgi complex, whereby it affects the architecture of the organelle (Aebersold et al. 2004; Shaul and Seger 2006). Modulation of ERK1c expression influences mitotic Golgi fragmentation, which in turn modulates mitosis progression. These features are unique to ERK1c, as these effects were not carried out by the main ERK1 protein. These findings shed a new light on research by other laboratories that previously demonstrated an involvement of the ERK cascade in the regulation of Golgi fragmentation without participation of doubly phosphorylated ERK1/2 (Acharya et al. 1998; Colanzi et al. 2000; Cha and Shapiro 2001). Interestingly, the kinetics and rate of ERK1c phosphorylation upon distinct stimulations are different from that of ERK1/2 (Shaul and Seger 2006), and, therefore, the protein kinases that phosphorylate ERK1c and their mechanism of action are still obscure.

We studied the possibility that ERK1c is phosphorylated mainly by MEK1b and not MEK1/2. Although MEK1b was suggested to be an inactive kinase toward ERK1/2, we found that it is, in fact, active toward ERK1c. MEK $1 \mathrm{~b}$ is mainly activated upon nocodazole treatment, whereas MEK1/2, which are mainly activated by mitogenic agents, are not activated by this stimulant. Modulation of expression and activation levels of MEK1b, but not of MEK1, affects ERK1c activation, as well as Golgi fragmentation and mitotic rate. Thus, ERK1c lies specifically downstream from MEK1b, while MEK1/2 preferentially phosphorylate ERK1/2. Therefore, this study provides evidence that during mitosis, the ERK cascade is split into two routes-the known MEK1/2-ERK1/2 that regulates several processes, such as CDC25 phosphorylation (Wang et al. 2007); and an alternative cascade composed of MEK1b and ERK1c that specifically regulates Golgi fragmentation. Thus, alternatively spliced isoforms of components of the ERK cascade can form an alternative signaling route. This may join other mechanisms, such as duration and strength of the signal (Shaul and Seger 2007), as a general way of regulating specificity determinants that allow induction of so many distinct, and even opposing, cellular processes downstream from Ras.

\section{Results}

ERK1c phosphorylation in mitosis is preferentially mediated by the alternative spliced MEK1b

It is well established that the ERK signaling cascade plays a role in the regulation of $\mathrm{G}_{2} / \mathrm{M}$ progression (for review, see Chambard et al. 2007). One of the $\mathrm{G}_{2} / \mathrm{M}$-related processes regulated by the ERK cascade is Golgi fragmentation (Acharya et al. 1998), and we showed previously that this process is regulated by ERK1c and not ERK1/2 (Shaul and Seger 2006). Interestingly, the kinetics and mode of ERK1c activation were distinct from that of ERK1/2 (Shaul and Seger 2006), and therefore it became important to identify the unique mechanism of ERK1c activation. We thus examined whether MEK1/2, or the presumably inactive MEK1b, participate in ERK1c activation. We first tested MEKs phosphorylation upon nocodazole treatment, which differentially stimulates ERK1c but not ERK1/2, as was previously shown by the specific detection with anti-pERK antibody $(\mathrm{Ab})$ (Shaul and Seger 2006). For this purpose, GFP-conjugated constructs of MEK1b, MEK1, and MEK2, as well as GFP control, were transfected into HeLa cells, and this was followed by either nocodazole or mock treatments. Western blotting with anti-pMEK $\mathrm{Ab}$ revealed that MEK1b-GFP is the main overexpressed phosphorylated MEK (Fig. 1A). Interestingly, two endogenous proteins were recognized by the anti-pMEK $\mathrm{Ab}$ as well, and this was reproduced with a similar $\mathrm{Ab}$ from another source. One of the identified proteins is the $35-\mathrm{kDa}$ nucleoplasmin (NPM), which is expressed mainly during the $\mathrm{G}_{2} / \mathrm{M}$ phase of the cell cycle. Importantly, although this protein does not have a significant resemblance to MEKs, it is nonspecifically recognized by all anti-pMEK Abs (Cha et al. 2004). The other, more interesting band was a weak $42-\mathrm{kDa}$ band that was elevated by the treatment and is likely to be the endogenous MEK1b. Since the phosphorylation of MEK1/2 is mediated under most conditions by Raf kinases (Shaul and Seger 2007), we examined whether MEK1b may be phosphorylated downstream from these kinases as well. Indeed, we found that phosphorylation of MEK1b upon nocodazole treatment is inhibited by the selective Raf inhibitor Sorafenib (Supplemental Fig. S1). Thus, in similarity to ERK1c, which is the main nocodazole-activated ERK, MEK1b is the main MEK isoform phosphorylated under the same conditions, and this is mediated, at least in part, by the upstream Raf kinases. 


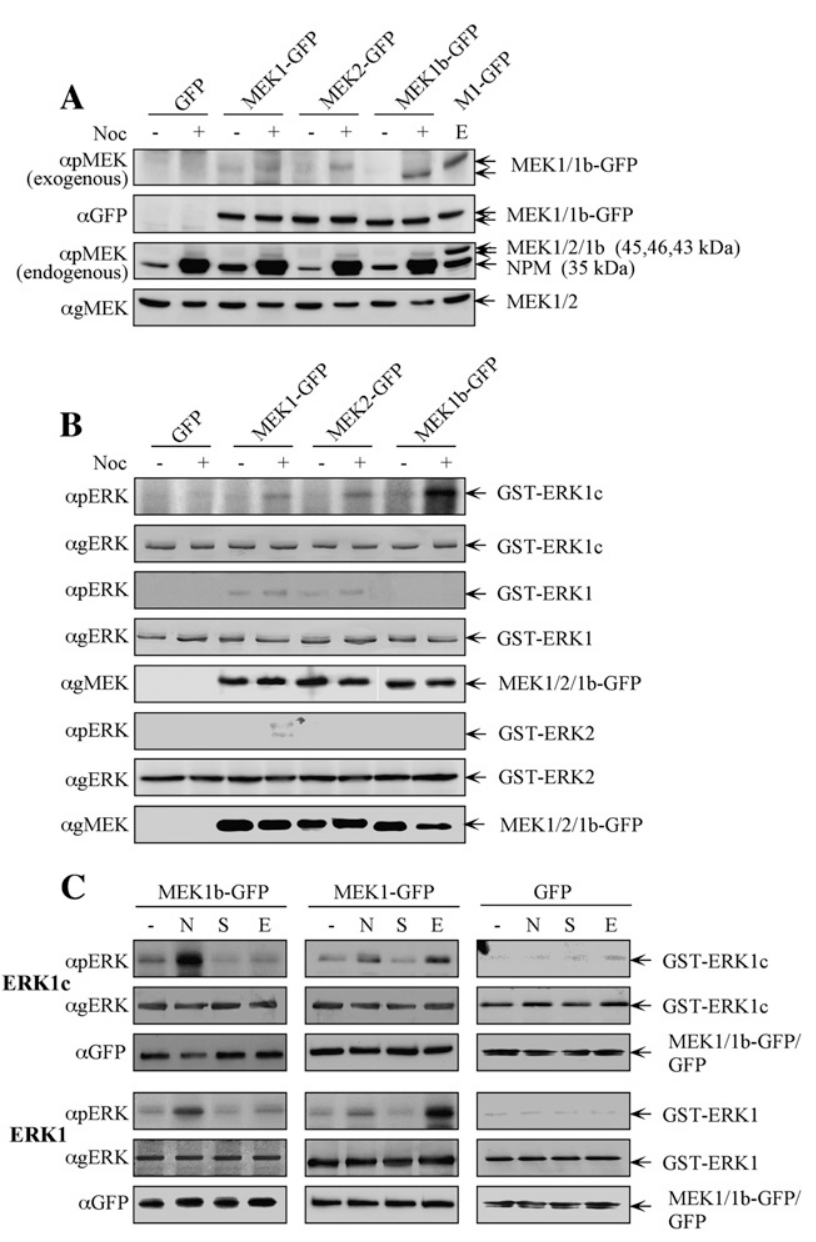

Figure 1. ERK1c phosphorylation in mitosis is preferentially mediated by the alternative spliced MEK1b. (A) MEK1b undergoes phosphorylation during mitosis. HeLa cells were transfected with GFP, MEK1-GFP, MEK2-GFP, or MEK1b-GFP. Each of these transfected cells was treated as follows: untreated $(-)$, nocodazole $[100$ $\mathrm{ng} / \mathrm{mL}, 24 \mathrm{~h}(+)]$, or serum-starved; and then stimulated with EGF [50 $\mathrm{ng} / \mathrm{mL}, 3 \mathrm{~min}(\mathrm{E})]$. The cells were harvested and subjected to Western blotting with anti-pMEK, anti-GFP, and anti-gMEK(C-18) Abs. (B) MEK1b preferentially phosphorylates ERK1c during mitosis. HeLa cells were transfected as in $A$. The cells were treated with nocodazole $[100 \mathrm{ng} / \mathrm{mL}, 24 \mathrm{~h}(+)]$ or left untreated $(-)$. The cells were then harvested, and the GFP proteins were immunoprecipitated with anti-GFP Ab. The precipitated proteins were subjected to an in vitro phosphorylation system using GST-ERK1, 2 and $1 \mathrm{c}$ as substrates, as described in the Materials and Methods. The amounts of ERK1, 2 and $1 \mathrm{c}$ as well as their phosphorylation levels were determined by Western blotting using $\alpha \mathrm{pERK}$, and $\alpha \mathrm{gERK}(\mathrm{CRS})$ Abs. The relative amounts of MEKs were determined by anti-gMEK(C-18) Ab, the MEKs used to phosphorylate ERK1/1c are in panel 5, and for ERK2 are in panel 8. (C) Differences between MEK1b and MEK1 stimulation and substrate determination. HeLa cells were transfected with MEK1b-GFP, MEK1-GFP, or GFP. The cells were treated as follows: untreated $(-)$, nocodazole $[100 \mathrm{ng} / \mathrm{mL}, 24 \mathrm{~h}(\mathrm{~N})]$, serum-starved [16 h $0.1 \%$ FCS, (S)], or serum-starved and then stimulated with EGF $[50 \mathrm{ng} / \mathrm{mL}, 3 \mathrm{~min}(\mathrm{E})]$. The cells were harvested and the GFP-tagged proteins were immunoprecipitated by $\alpha \mathrm{GFP} A b$, and each one of them was subjected to an in vitro phosphorylation using GSTERK1/1c as substrates. The amounts of ERK1/1c as well as their phosphorylation levels were determined by Western blotting using anti-pERK, anti-gERK(CRS), and anti-GFP Abs.
In an effort to further evaluate the role of MEK1b as a major ERK1c kinase, we compared the ability of the various MEKs to phosphorylate the regulatory Thr and Tyr in ERK1c. Thus, we precipitated the GFP-MEKs from nocodazole-stimulated and untreated cells and subjected them to an in vitro phosphorylation reaction with purified GST-ERK1c, GST-ERK1, and GST-ERK2 as substrates. The nocodazole-treated MEK1b phosphorylated ERK1c much stronger than MEK1/2, while no phosphorylation of ERK1 could be detected (Fig. 1B). On the other hand, MEK1 slightly phosphorylated ERK1 and ERK2; MEK2 phosphorylated only ERK1; and as would be expected from the minor ERK1/2 activation (Shaul and Seger 2006), these phosphorylations were only slightly stimulated upon nocodazole treatment. Thus, MEK1b, previously suggested to be an inactive kinase (Zheng and Guan 1993), is, in fact, active toward ERK1c and is likely to be the main activator of ERK1c during mitosis.

To further link the activation of MEK1b with that of ERK1c, we also studied the EGF-induced activation of MEK1b, as compared with MEK1. Thus, we overexpressed GFP-MEK1, GFP-MEK1b, or GFP alone as control in HeLa cells and either left the cells untreated, or treated them with nocodazole. Alternatively, the transfected cells were serum-starved and then left either untreated or stimulated with EGF. The exogenous MEKs were then immunoprecipitated by anti-GFP $\mathrm{Ab}$ and used to phosphorylate either GST-ERK1c or GST-ERK1. Upon nocodazole treatment, MEK1b demonstrated high activity toward ERK1c, but only a minor activity toward ERK1 (Fig. 1C). However, upon EGF treatment, the activity of MEK1b toward ERK1c was marginal, and the activity toward ERK1 was not stimulated. On the other hand, EGF stimulated the MEK1-activated ERK1 but had much less effect on ERK1c. These results further demonstrate a differential regulation in which EGF primarily activates MEK1/2, which are specific to ERK1/2, while nocodazole primarily stimulates MEK1b, which is specific to ERK1c.

\section{In vitro phosphorylation reveals that $M E K 1 b$ is a specific ERK1c kinase, while MEK1 prefers ERK1}

To obtain an insight into the kinetic parameters of ERK1c and ERK1 phosphorylation by MEK1b and MEK1, we used recombinant active MEKs, purified from bacteria. Thus, we prepared the construct 6 His- $\Delta$ N-EE-MEK1b, which by analogy to the previously published 6 His- $\Delta \mathrm{N}$ EE-MEK1 (Mansour et al. 1996; Jaaro et al. 1997) should be constitutively active. This construct, as well as 6 His$\triangle$ N-EE-MEK1, was then tested for their ability to doubly phosphorylate ERK1c or ERK1. A calibration curve, containing three distinct amounts of bacterially expressed pERK2 (Yung et al. 1997), was added to each of the Western blots to allow for a similar exposure and comparison between the phosphorylation levels in the different experiments. Under these conditions, the activity of MEK1b toward ERK1c was $\sim 15$-fold higher than toward ERK1 (Fig. 2A,B), while MEK1 phosphorylated ERK1 $\sim 10$-fold better than ERK1c. In addition, the phosphorylation 
Shaul et al.
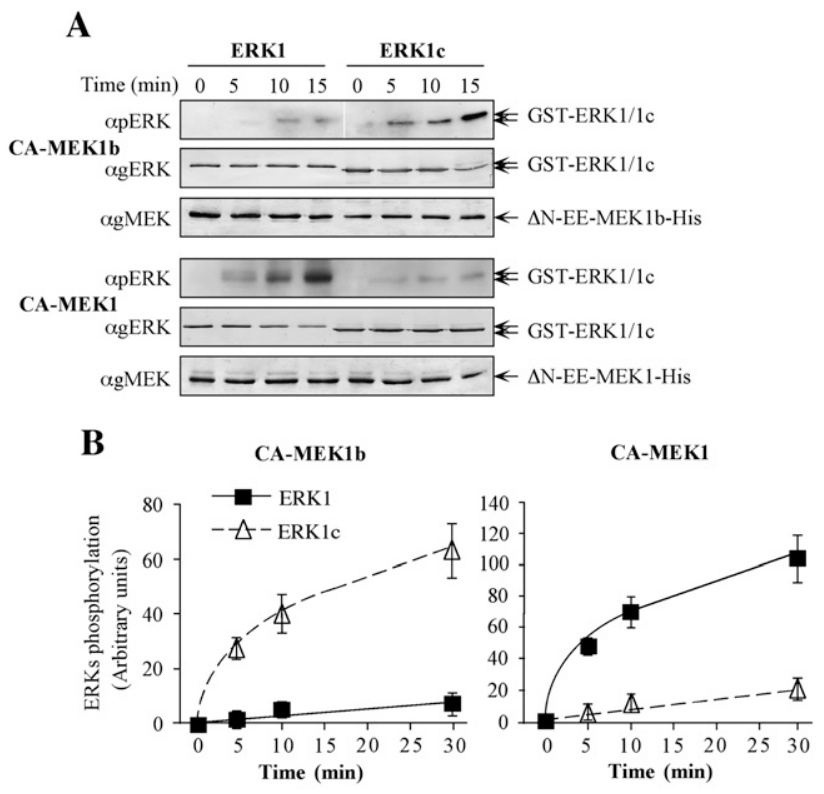

C

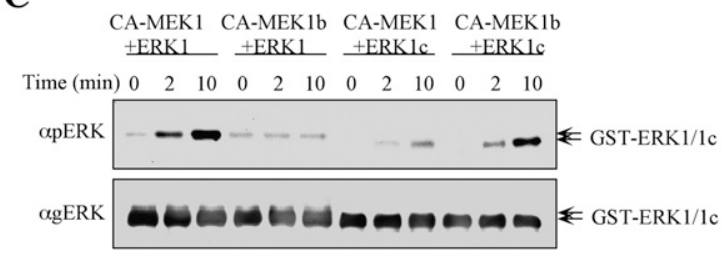

Figure 2. Specificity studies using constitutively active MEK1b and MEK1. (A) Time course of ERK1 and ERK1c phosphorylation by constitutively active MEK1b and MEK1. In vitro phosphorylation was preformed as described under Materials and Methods with recombinant His- $\Delta$ N-EE-MEK $1 b$ and His- $\Delta$ N-EEMEK1 as kinases and GST-ERK1 and GST-ERK1c as substrates. The amounts of ERK1/1c and their phosphorylation levels were determined by Western blotting with anti-pERK, anti-gERK(CRS), and anti-gMEK(C-18) Abs. (B) Quantification of ERK1/1c phosphorylation. Known amounts of phosphorylated ERK were added to the blots to form a calibration curve, which enabled the determination of ERK1/1c phosphorylation levels (see text for details). The results in the graphs represent means \pm SE of three experiments. (Squares) ERK1 phosphorylation; (triangles) ERK1c phosphorylation. $(C)$ Side-by-side kinetics of ERK1/1c dual phosphorylation by MEK1/1b. In vitro phosphorylation was performed using amounts of recombinant proteins that were found optimal for each phosphorylation [His- $\Delta$ N-EE-MEK1 (CA-MEK1), $0.5 \mu \mathrm{g}$ per reaction; His- $\Delta$ N-EE-MEK1b (CA-MEK1b), $0.75 \mu \mathrm{g}$; GSTERK1, $0.5 \mu \mathrm{g}$ or GST-ERK1c $0.5 \mu \mathrm{g}$ ] for 0,2 , and $10 \mathrm{~min}$ at $30^{\circ} \mathrm{C}$ as described in the Materials and Methods. The levels of ERK1/1c phosphorylation were detected by resolving the samples by one SDS-PAGE and Western blotting using anti-pERK, and anti-gERK(CRS) Abs.

of ERK1c by MEK1b was about fivefold higher than by MEK1, while MEK1 phosphorylated ERK1 30-fold higher than MEK1b. The relative phosphorylation rates, which were obtained by using different SDS gels with calibration curves, were verified by comparing some of the samples side-by-side on one SDS gel (Fig. 2C).
To validate the results with the recombinant proteins, we also used immunoprecipitation of stimulated MEK1GFP or MEK1b-GFP that were overexpressed in HeLa cells (Supplemental Fig. S2). Maximal stimulation was achieved by stimulating MEK1b-GFP-containing cells with nocodazole and MEK1-GFP-expressing cells with EGF. The stimulated MEKs were then immunoprecipitated, stringently washed, and used to phosphorylate GST-ERK1c or GST-ERK1 in vitro. As above, we added calibration curves of bacterially expressed pERK2 to each of the Western blots to allow similar exposures. As expected, MEK1b phosphorylated ERK1c much better than ERK1, while MEK1 preferentially phosphorylated ERK1. In addition, the rate of ERK $1 \mathrm{c}$ phosphorylation by MEK $1 \mathrm{~b}$ was much better than that by MEK1, while MEK1 phosphorylated ERK1 much better than MEK1b. When U0126 was added, it significantly inhibited both MEKs, confirming that the ERK1/2 phosphorylation was indeed executed by MEKs. Taken together, our results indicate that MEK1b, which was thought previously to be an inactive kinase (Zheng and Guan 1993), is indeed only marginally active toward ERK $1 / 2$ but can serve as an active kinase of ERK1c.

\section{Endogenous MEK1b is activated by nocodazole and specifically phosphorylates ERK1c}

Since the above experiments were performed with recombinant MEK1b, it was important to show that the endogenous protein exhibits similar characteristics. For this purpose, we fractionated extracts from nocodazole-treated HeLa cells (Fig. 3A) from cells in $\mathrm{G}_{2} / \mathrm{M}, 9 \mathrm{~h}$ after release from double-thymidine block and from untreated cells (data not shown) on a Mono-Q FPLC column. In all columns, MEK1b was eluted by similar $\mathrm{NaCl}$ concentrations (0.09-0.13 M, fractions 40-47), while MEK1/2 were eluted in the flow-through. With the use of anti-pMEK Ab, we found that the endogenous MEK1b as well as MEK1/2 from nocodazole-treated and thymidine-released cells were phosphorylated on their activitory Ser residues. However, as would be expected from the results with overexpressed constructs (Fig. 1), the specific phosphorylation of MEK1b was much higher than that of MEK1, and both of them were not phosphorylated in untreated cells (Fig. 3B,C). No significant amount of a $35-\mathrm{kDa}$ band was detected in any of the fractions by the anti-pMEK $A b$, indicating that NPM, expressed in $G_{2} / M$ cells (Fig. 1), was either degraded or eluted by higher $\mathrm{NaCl}$ concentrations. Importantly, when the activity of MEKs was assayed, the fractionated MEK1b from both nocodazole-treated and from thymidine-released cells, but not from unstimulated cells, phosphorylated ERK1c and to a much lower extent also ERK1 (Fig. 3D,E). MEK1/2, which is activated to a lesser extent by nocodazole or after release from double-thymidine block, did not significantly phosphorylate ERK1c under these conditions. These results are in agreement with the results with overexpressed MEKs, supporting again the specific role of endogenous MEK1b in the activation of ERK1c during $\mathrm{G}_{2} / \mathrm{M}$. 
A
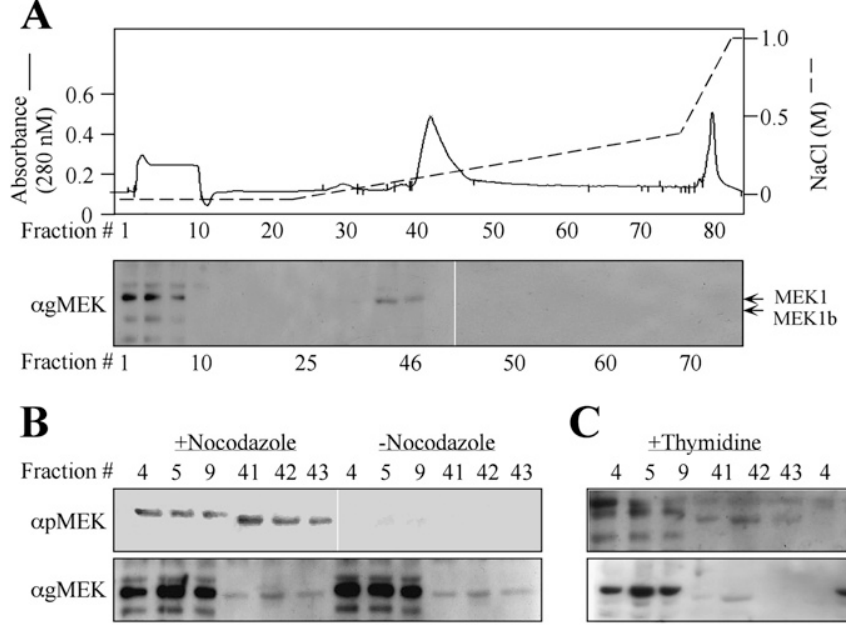

C

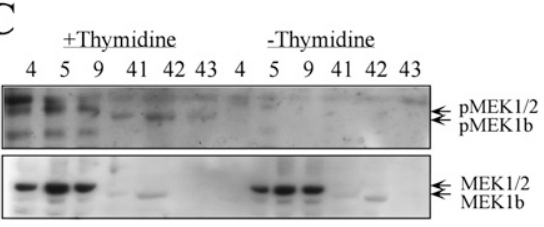

D

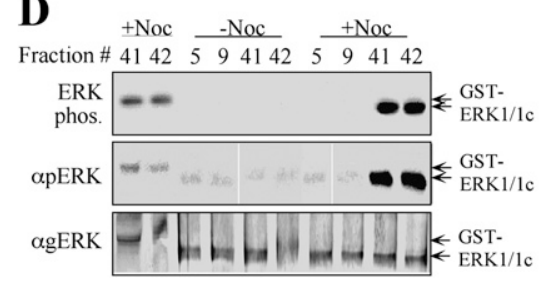

Figure 3. Fractionation of endogenous MEK1b verifies its specificity toward ERK1c. (A) Fractionation of MEK1b on a Mono-Q FPLC column. HeLa cells (10 plates of $10 \mathrm{~cm}$ ) were treated with nocodazole $(100 \mathrm{ng} / \mathrm{mL}, 24 \mathrm{~h})$ and harvested in Buffer A. Cell extracts were loaded onto a Mono-Q FPLC column, which was washed with Buffer A and developed using an increasing $\mathrm{NaCl}$ gradient (dashed line), to give rise to the protein profile shown by the solid line. Aliquots $(40 \mu \mathrm{L}$, boiled in sample buffer) of every third fraction were subjected to Western blotting with antigMEK(H-8) Abs. Identical fractionation of MEK1/2 and MEK1b was observed with extracts from HeLa cells that were harvested $9 \mathrm{~h}$ after release from double-thymidine block and from untreated cells (data not shown). $(B, C)$ Endogenous MEK1b from $\mathrm{G}_{2} / \mathrm{M}$ cells is phosphorylated on its regulatory residues. Fractions containing MEK1/2 $(\# 4, \# 5, \# 9)$ or MEK1b (\#41, \#42, \#43) from cells that underwent treatment with nocodazole as described above $(B), 9 \mathrm{~h}$ after release from double-thymidine block as described above $(C)$, or untreated cells $(B, C$, indicated fractions) were subjected to Western blotting with anti-pMEK (top panel) and anti-gMEK(H-8) Ab (bottom panel). Similar results were obtained with $\mathrm{Ab}$ from other companies (data not shown). (D,E) The endogenous activated $M E K 1 b$ from $G_{2} / M$ cells phosphorylates mainly ERK1c in vitro. The indicated aliquots of $M E K 1 / 2$ - or MEK1b-containing fractions from nocodazole-treated cells $(D)$, from cells that were released from double-thymidine block $(E)$, or from untreated cells $(E, D$, indicated fractions) were used to phosphorylate GST-ERK1c $(0.5 \mu \mathrm{g})$ or GST-ERK1 $(0.5 \mu \mathrm{g})$, as described in Material and Methods. The phosphorylated proteins were analyzed by autoradiography (top panels) or by Western blotting with anti-pERK and anti-gERK(CRS) Abs (bottom panels) as indicated.

\section{Modulation of MEKs expression verifies MEK1b and MEK1 specificities in vivo}

In order to verify that the specificities of MEK1b and MEK1 toward ERK1c and ERK1 occur also in vivo, we modulated MEK1 and MEK1b levels by either overexpression or specific Sh-RNAs' knockdown. The transfected cells were stimulated with nocodazole, ERK1c and ERK1 were each immunoprecipitated, and their activities were determined using myelin basic protein (MBP) as a substrate. As reported (Shaul and Seger 2006), ERK1c was strongly activated upon nocodazole treatment of HeLa cells, while U0126 prevented this effect (Fig. 4A,B). Overexpression of MEK1b slightly elevated ERK1c activity, while overexpression of MEK1 had no significant effect. The fact that overexpression of MEK1b had only a small effect could be explained by saturation in the kinase levels, as was previously reported for the effects of MEK1 toward ERK1/2 (Seger et al. 1992). On the other hand, reduced MEK $1 \mathrm{~b}$ expression (Fig. 4C) gave a stronger effect, as its Sh-RNA (Sh-MEK1b) transfection significantly reduced ERK1c activity (Fig. 4A,B). The influence of Sh-MEK1b was not due to any off-target effects, as revealed by rescue experiments using expression of WTMEK1b in cells containing Sh-MEK1b (data not shown). As expected from our results above, Sh-RNA of MEK1 had only a small effect on ERK1c activity, and ERK1 activity was not significantly altered, mainly due to lack of sensitivity to nocodazole treatment.

\section{The expression levels and activity of MEK1b are elevated during mitosis}

Our findings indicate that MEK1b regulates ERK1c activity, and ERK1c expression and activity are elevated in mitosis (Shaul and Seger 2006). Therefore, we examined whether MEK1b activity indeed correlates with that of ERK1c. For this purpose, we synchronized HeLa cells, using a double-thymidine block (Merrill 1998). FACS analysis (data not shown) and mitotic index determination (Fig. 5A) revealed that most of the cells are found in $\mathrm{G}_{2}$ within $6 \mathrm{~h}$, in mitosis after $10 \mathrm{~h}$, and cycled back to the next $\mathrm{G}_{1}$ within 11-12 $\mathrm{h}$. We then examined the behavior of MEK $1 \mathrm{~b}$ as compared with MEK1/2 in the synchronously cycling cells, $6 \mathrm{~h}\left(\mathrm{G}_{2}\right), 9 \mathrm{~h}\left(\mathrm{G}_{2} / \mathrm{M}\right), 10 \mathrm{~h}$ (peak mitosis), and $11 \mathrm{~h}$ (late mitosis/early $\mathrm{G}_{1}$ ) after release. Western blotting with anti-MEK Ab showed that MEK1b levels are increased during $\mathrm{G}_{2} / \mathrm{M}$ and mitosis, while the expression levels of MEK1/2 were constant during the times examined (Fig. 5B). In addition, blotting with antipMEK $\mathrm{Ab}$ revealed that the phosphorylation of endogenous MEK1b, and to some extent endogenous MEK1/2, 


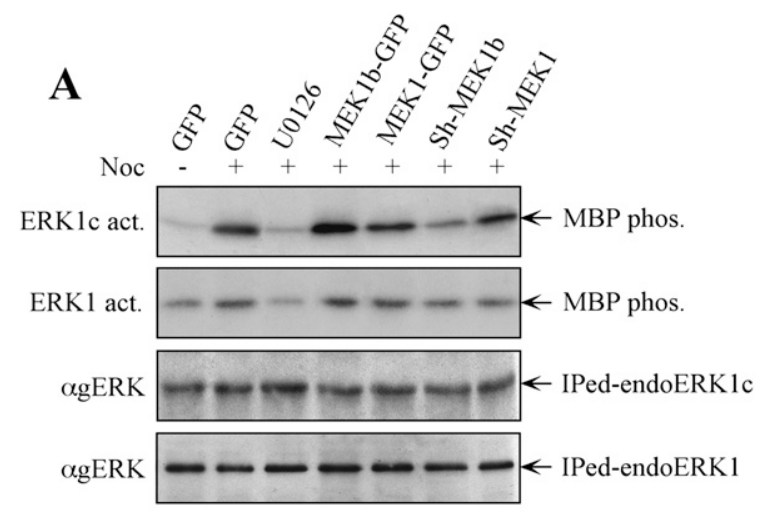

B

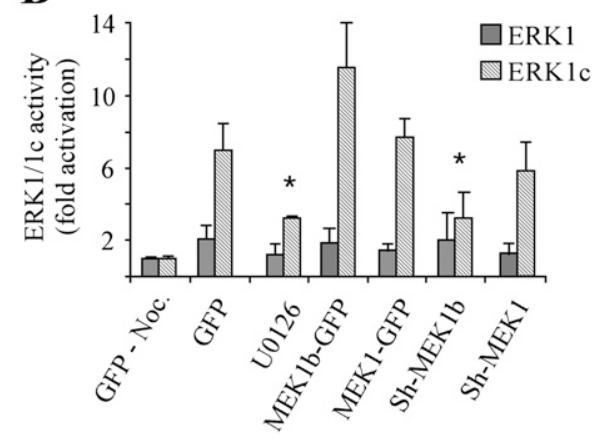

C

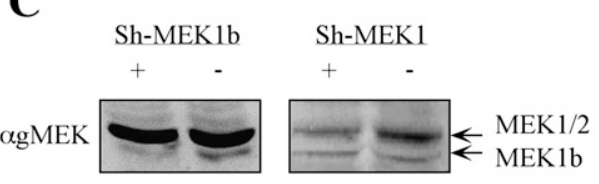

Figure 4. Modulation of MEK1b expression affects nocodazoledependent ERK1c activity in vivo. (A) HeLa cells were transfected as follows: GFP, MEK1b-GFP, MEK1-GFP, Sh-MEK1b, and Sh-MEK1. The cells were treated with nocodazole $[100 \mathrm{ng} / \mathrm{mL}$, $24 \mathrm{~h},(+))$. The MEK inhibitor U0126 $(5 \mu \mathrm{M}, 1 \mathrm{~h})$ was added prior to the cell harvesting. The cells were harvested, and endogenous ERK1 or ERK1c was immunoprecipitated. The precipitated proteins were subjected to in vitro phosphorylation using MBP as a substrate (ERK1c and ERK1 act.). The amounts of immunopreipitated endogenous ERKs (immunoprecipitated endoERK1 and ERK1c) were determined by Western blotting using antigERK(CRS) Ab. (B) Quantification of kinase activation. Fold activations of ERK1c and ERK1 were quantified by densitometry and presented as means \pm SE of three experiments. All bargraphs, except of the first two, represent stimulation with nocodazole. A Student's $t$-test was used to determine statistical significance $\left(\left[{ }^{\star}\right] P<0.05\right)$. (C) Specific knockdown of MEK1b and MEK1 by their corresponding Sh-RNAs. HeLa cells were transfected with a plasmid containing Sh-RNA of MEK1b (Sh-MEK1b, +), MEK1 (Sh-MEK1, +), or a control plasmid (-). Forty-eight hours after transfection, the cells were harvested and subjected to SDSPAGE and Western blotting with anti-gMEK (H-8) Abs.

was elevated during the same time. The fact that the higher pMEK $1 \mathrm{~b}$ is due to specific phosphorylation, and not elevated expression, was verified by equilibrating the amount of MEK1b in the different lanes. Indeed, also under these conditions, MEK1b phosphorylation was much higher 9 and $10 \mathrm{~h}$ after the block release (Fig. 5C), indicating that, similar to ERK1c, both the expression and MEK1b activity are elevated during mitosis.

We then examined whether the phosphorylation of MEKs is accompanied by their expected elevated activity during cell cycle progression. Accordingly, MEK1b-GFP and MEK1/2-GFP were each expressed in HeLa cells that were synchronized using the double-thymidine block. After block release, the proteins were immunoprecipitated and used to phosphorylate ERK1c (for MEK1b) and ERK1 (for MEK1). Nonsynchronized cells were found to contain a relatively low activity of MEK1b and MEK1 (Fig. 5D). However, the activity of MEK1b was significantly increased at $G_{2} / M$, while the activity of MEK1 increased only at the end of $G_{2}$. Thus, MEK1b behavior correlates with that of ERK1c (Shaul and Seger 2006) in their mitotic expression levels and activities, while MEK1 activity correlates better with that of ERK1/2. On the other hand, the lack of MEK1 activation by nocodazole, which correlates with the lack of ERK1/2 activation under these conditions (Takenaka et al. 1998), could be due to the fact that nocodazole arrests cells in metaphase, and at this stage, the activity of MEK $1 / 2$ and ERK $1 / 2$ is already reduced after peaking at the $\mathrm{G}_{2} / \mathrm{M}$ phase.

\section{MEK1b induces Golgi fragmentation via ERK1c}

In our previous studies, we showed that ERK1c can be accumulated in the Golgi and cause its fragmentation (Aebersold et al. 2004; Shaul and Seger 2006). Since our results above demonstrated that MEK1b is a main ERK1c regulator, we examined whether elevation of its expression and activity would affect the Golgi architecture as well. Thus, we overexpressed GFP-tagged MEK1, MEK1b, $\Delta \mathrm{N}$-EE-MEK1, and $\Delta \mathrm{N}$-EE-MEK1b in HeLa cells, which were subsequently stained with the Golgi marker p58 (Hendricks et al. 1991). As expected, GFP-MEK1b was localized mainly in the cytoplasm (Fig. 6A), while $\Delta$ N-EEMEK1b was spread all over the cells, similar to MEK1 constructs distribution (Jaaro et al. 1997). We then analyzed the Golgi architecture and found that overexpression of MEK1-GFP, and as reported (Acharya et al. 1998), $\triangle$ N-EE-MEK1-GFP elevate Golgi fragmentation to some extent, possibly due to its mislocalization of a very active kinase that allows ERK1c activation (Fig. 6A). However, overexpression of MEK1b-GFP or $\triangle$ N-EE-MEK1b-GFP significantly increased the percentage of cells with fragmented Golgi. In order to verify that the effects of MEK1b are indeed mediated by ERK1c, we overexpressed $\triangle$ N-EEMEK1b-GFP together with the Sh-RNA of either ERK1 or ERK1c. As reported (Shaul and Seger 2006), Sh-RNA of ERK1c, but not that of ERK1, inhibited the MEK1binduced fragmentation (Fig. 6B). Other constructs that had smaller effects on Golgi fragmentation of cycling cells were ERK1c and MEK1b, as well as their Sh-RNAs, while modulation of ERK1 and MEK1 expression had no effect (data not shown). Quantification of these results showed that, indeed, the effects of ERK1c, MEK1b, $\Delta \mathrm{N}$ EE-MEK $1 \mathrm{~b}$, and $\Delta \mathrm{N}$-EE-MEK $1 \mathrm{~b}$ plus Sh-ERK1c are statistically significant (Fig. 6C). Thus, MEK1b, but not MEK1, is able to regulate Golgi fragmentation via ERK1c, verifying 
A

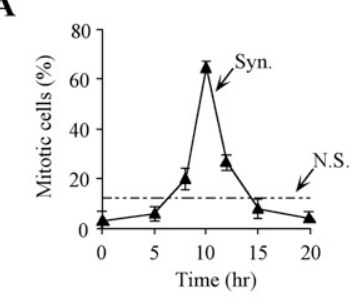

B
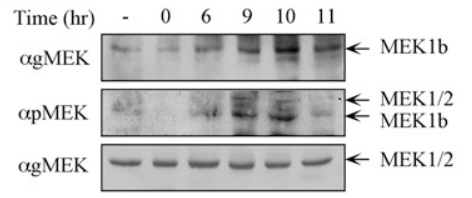

C

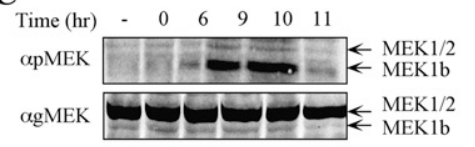

D

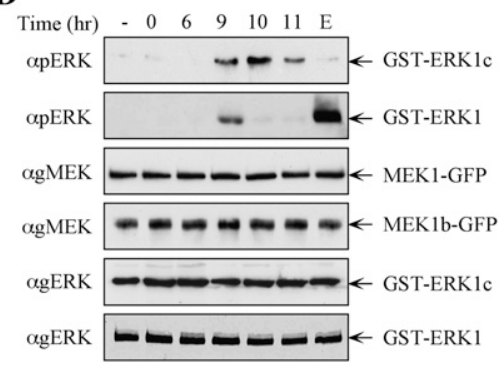

Figure 5. The expression levels and activity of MEK1b are elevated during mitosis. HeLa cells were synchronized by a double-thymidine block, followed by the removal of the block to enable cell cycle progression (Syn), or left untreated (nonsynchronized, N.S.) as a control. (A) Mitotic index determination. The cells were fixed and stained with DAPI. The percentage of mitotic cells out of the total number of nuclei counted is presented as the means $\pm \mathrm{SE}$ of three experiments; $N=300$. $(B)$ MEK $1 b$ expression and phosphorylation are elevated in the $G_{2} / M$ phase of the cell cycle. The cells were harvested and subjected to Western blotting with anti-gMEK(H-8) and anti-pMEK Abs. For a better resolution of the MEK1b, SDS-PAGE was longer than in previous experiments. Exposure times for gMEK1/2 and gMEK1b were different. $(C)$ Specific MEK1b phsphorylation is elevated during mitosis. Equal amounts of MEK1b (judged by a calibrating Western blot) from each time after block release were subjected to Western blotting with anti-pMEK Ab. $(D)$ MEK1b activity is enhanced in the $G_{2} / M$ phase of the cell cycle. HeLa cells were transfected with MEK1b-GFP or MEK1-GFP. The cells were synchronized by double-thymidine block, and times after release are indicated. In addition, one plate was serum-starved and stimulated with EGF ( $50 \mathrm{ng} / \mathrm{mL}$, 3 min; E). The cells were harvested, and MEK1b or MEK1 was immunoprecipitated using anti-GFP $\mathrm{Ab}$. The immunoprecipitated proteins were used as kinases for in vitro phosphorylation, where GST-ERK1c served as a substrate for MEK1b and GST-ERK1 for MEK1. The amounts of ERK1/1c as well as their phosphorylation levels were determined by Western blotting using anti-pERK, anti-gMEK(H-8), and anti-gERK(CRS) Abs. that both MEK1b and ERK1c participate in the regulation of Golgi fragmentation.

Importantly, the effects of MEK1b were not restricted to HeLa cells that were used in all the above experiments. Thus, nocodazole treatment of HEK293T cell resulted in TEY phosphorylation of ERK1c in a MEK-dependent manner, whereas ERK1 or ERK2 was only slightly phosphorylated (Supplemental Fig. S3). Similar results were also seen in COS7 cells (data not shown). In addition, the release of a double-thymidine block showed that the expression and phosphorylation of MEK1b, but much less of MEK1/ 2 , are elevated in $\mathrm{G}_{2} / \mathrm{M}(9-11 \mathrm{~h}$ after release). Finally, in correlation to Sh-ERK1c, Sh-MEK1b (but not Sh-MEK1) reduced the number of cells with fragmented Golgi, as shown above in HeLa cells. Together, these results indicate that the MEK1b/ERK1c role in Golgi fragmentation is general and not restricted to HeLa cells.

We showed previously that ERK1c regulates Golgi fragmentation particularly during mitosis (Shaul and Seger 2006), and, therefore, it was important to demonstrate that MEK1b can induce the same effects. For this purpose, we modulated MEK1b expression by overexpressing its GFP-tagged form or knocking it down by Sh-RNA, and followed Golgi architecture with the Golgi marker p58. As expected from the ERK1c results (Shaul and Seger 2006), elevated MEK1b expression levels increased the number of cells with fragmented Golgi, especially during prophase (Fig. 7). Lowering MEK1b expression significantly reduced the percentage of cells with fragmented Golgi during prophase, prometaphase, and modulated Golgi distribution during metaphase. Moreover, in correlation with the effect of Sorafenib on MEK1b activity (Supplemental Fig. S1), this Raf inhibitor also significantly reduced Golgi fragmentation (Supplemental Fig. S4). Therefore, these results strongly support a role of a specific MEK1b-ERK1c cascade downstream from Raf kinases, in the regulation of Golgi fragmentation during mitosis. Interestingly, brefeldin-A (BFA), which induces Golgi fragmentation by various mechanisms (Chardin and McCormick 1999|, induced Golgi fragmentation in our system as well (Supplemental Fig. S4) but failed to induce MEK1b activation (Supplemental Fig. S1). This indicates that the MEK1b-ERK1c cascade induces Golgi fragmentation only under selected conditions.

\section{$M E K 1 b$ regulates mitotic progression}

We then examined whether cellular MEK1b regulates mitotic progression as much as ERK1c (Shaul and Seger 2006). Therefore, the expression levels of MEK1b, MEK1, and ERK1c were modulated; the cells were synchronized with or without the MEK inhibitor U0126; and the cell cycle stage was determined by FACS. Thus, $6 \mathrm{~h}$ after block release, the various transfected cells were found in the $G_{2}$ phase of the cell cycle, indicating that neither MEK1b and MEK1, nor ERK1 and ERK1c play a role in S-to- $G_{2}$ progression of HeLa cells (Supplemental Fig. S5). On the other hand, $9 \mathrm{~h}$ after release, MEK $1 \mathrm{~b}$ had a marked influence on mitotic progression. Thus, overexpression of MEK1b promoted the mitotic progression, and knockdown 
A

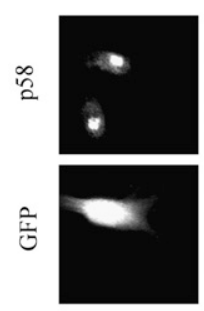

GFP

B

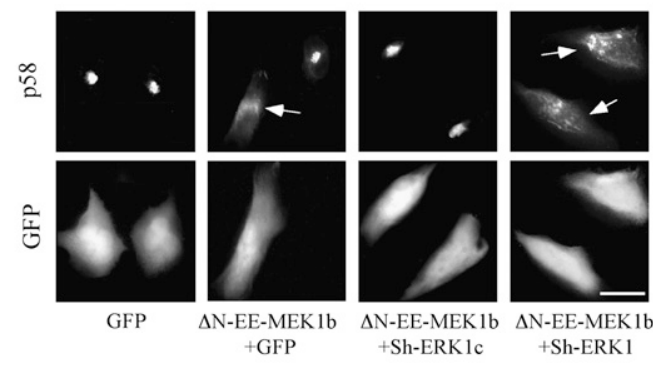

C

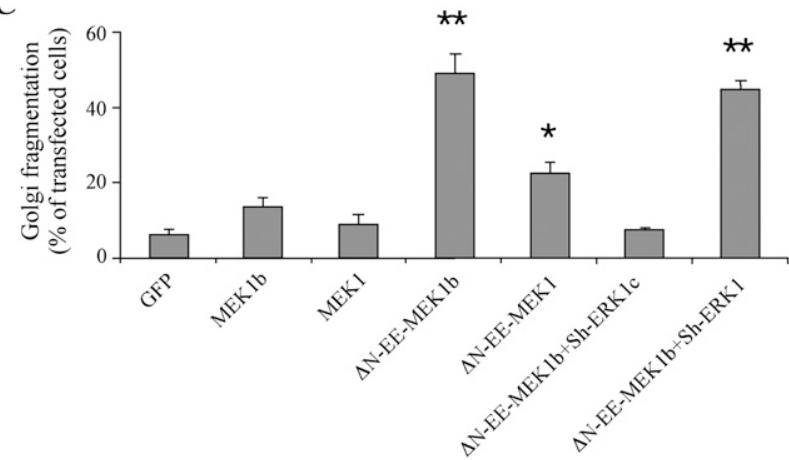

Figure 6. MEK1b induces Golgi fragmentation. $(A)$ The effect of MEKs constructs on Golgi architecture. HeLa cells were transfected with GFP, MEK1b-GFP (MEK1b), MEK1-GFP (MEK1), $\Delta \mathrm{N}$ EE-MEK1b-GFP ( $\Delta$ N-EE-MEK1b), or $\Delta$ N-EE-MEK1-GFP $(\Delta$ N-EEMEK1-GFP). Fourteen hours after transfection, the cells were fixed, stained with anti-p58 Ab, and visualized by a fluorescent microscope. Arrows indicate fragmented Golgi. Bar, $8 \mu \mathrm{m} .(B)$ ERK1c is required for MEK1b-induced Golgi fragmentation. HeLa cells were transfected with GFP alone as control or cotransfected with $\triangle$ N-EE-MEK1b-GFP together with GFP, ERK1c Sh-RNA (ShERK1c), or ERK1 Sh-RNA (Sh-ERK1). The cells were then fixed, stained with anti-p58 $\mathrm{Ab}$, and visualized by a fluorescent microscope. (Arrows indicate fragmented Golgi. Bar, $8 \mu \mathrm{m}$.) (C) Quantification of Golgi fragmentation. The HeLa cells in $A$ and $B$ were counted, and the percentage of fragmented Golgi per total transfected cells is presented. The results are means \pm SE of three experiments, $n=200$. A Student's $t$-test was used for statistical significance. $\left(^{\star}\right) P<0.05 ;\left(^{\star \star}\right) P<0.01$.

of MEK $1 b$ delayed the cells at $G_{2}$ with similarity to the U0126 treatment. In these experiments, MEK1 had no influence on these cell cycle parameters. These effects of MEK1b were mostly mediated by ERK1c, since the interfering construct of the latter, not of ERK1, significantly reduced the MEK1b-induced mitotic progression. These effects were restricted to $10-12 \mathrm{~h}$ after the block release, as no significant effect on cell cycle distribution was observed $13 \mathrm{~h}$ after the release. The effects on the cell cycle correlated well with the rate of Golgi fragmentation. Interestingly, the constitutively active MEK1 that did induce Golgi fragmentation (Fig. 6) also had a strong
A
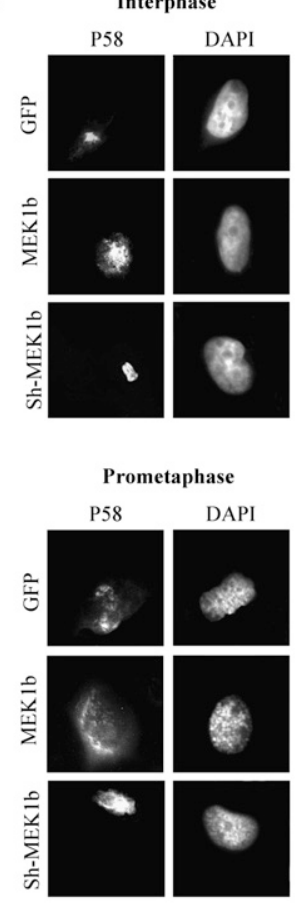

B

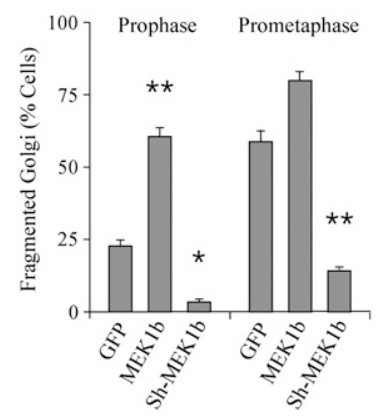

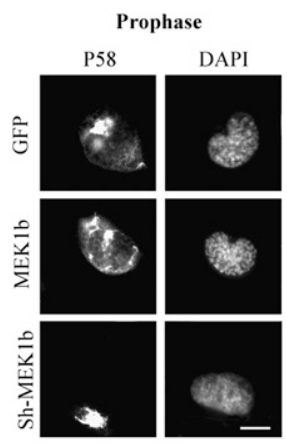
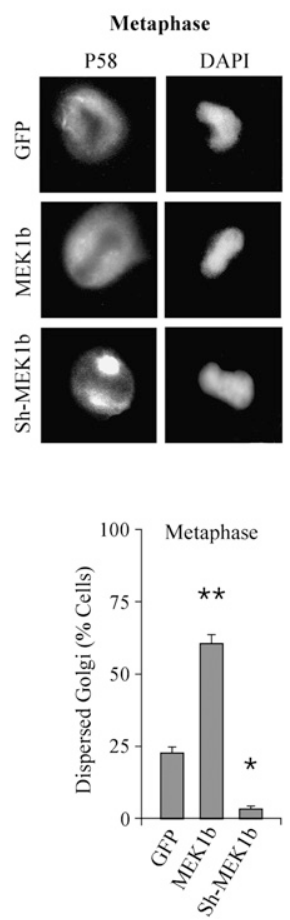

Figure 7. Modulation of MEK1b expression affects Golgi fragmentation during mitosis. $(A)$ MEK1b affects Golgi architecture during stages of mitosis. HeLa cells were transfected with GFP, GFP-MEK1b (MEK1b), or Sh-MEK1b with GFP (Sh-MEK1b). The cells were synchronized by double-thymidine block, and $9 \mathrm{~h}$ after the release from the block were stained with p58 Abs and DAPI. Cells from interphase, prophase, prometaphase, and metaphase were selected by their DNA structure. Bar, $5 \mu \mathrm{m} .(B)$ Quantification of Golgi fragmentation in prophase prometaphase and metaphase. The cells in prophase and prometaphase were counted, and the percentage of cells with fragmented Golgi out of total transfected cells is presented as means \pm SE of three experiments $(n=40)$. The cells in metaphase were counted, and the percentage of cells with partially intact Golgi per total transfected cells is presented as means \pm SE of three experiments. A Student's $t$-test was used to determine statistical significance. $\left(^{\star}\right) P<0.05 ;\left(^{\star \star}\right) P<0.01$. 
effect on mitotic progression, but this effect is likely to involve other processes besides Golgi fragmentation (Wang et al. 2007). The lack of effect of Sh-MEK1 and Sh-ERK1 on mitotic progression could be explained by the compensation of MEK2 or ERK2 that were not simultaneously reduced. Overall, our results suggest that MEK1b participates in the regulation of mitotic progression by affecting Golgi fragmentation, and this is mediated via ERK1c, which demonstrates similar effects. Therefore, these results provide another indication that these two kinases function within their own unique signaling cascade.

\section{Discussion}

In this study, we demonstrate a novel ERK signaling route, composed of the alternatively spliced forms MEK $1 \mathrm{~b}$ and ERK1c that specifically function during mitosis. We demonstrated previously that ERK1c plays a unique role in regulating Golgi fragmentation (Shaul and Seger 2006). Although the activation of ERK1c was inhibited by MEK inhibitors, its mode and kinetics of phosphorylation were distinct from those of ERK1/2, suggesting a different mechanism of activation of ERK1c. Therefore, we examined whether the alternatively spliced isoform of MEK1, namely, MEK1b (Seger et al. 1992; Zheng and Guan 1993), could be the upstream kinase of ERK1c. Indeed, we found that this isoform may be a specific ERK1c kinase, as concluded from the following results: (1) MEK1b is phosphorylated and activated better than MEK1/2 upon nocodazole treatment, correlating with the preferential activation of ERK1c over ERK1/2 (Shaul and Seger 2006). (2) Active MEK1b preferentially phosphorylated ERK1c in vitro, whereas active MEK1 phosphorylated ERK1 better. (3) Changes in MEK1b expression and activation levels modulated ERK1c, but not ERK1 activities. (4) In correlation with ERK1c, the expression levels and activity of MEK $1 \mathrm{~b}$ is enhanced during mitosis. (5) In correlation with ERK1c, modulation of MEK1b expression and activity affects Golgi fragmentation as well as the rate of mitosis. (6) MEK1b-induced Golgi fragmentation and mitotic progression is inhibited by ERK1c, but not ERK1 knockdown. These findings strongly suggest the existence of two distinct signaling routes-one is composed specifically from MEK1b-ERK1c, and the other contains MEK1ERK1/2, with a very little cross-talk between them.

MEK1b was suggested to be an inactive form of MEK1 (Zheng and Guan 1993), as it failed to phosphorylate ERK1/2 upon EGF and TPA stimulation. Indeed, in our study, we showed that it exhibits only a marginal activity toward ERK1/2, but we demonstrated that MEK1b is activated during mitosis, when it phosphorylates primary ERK1c. Thus, the elimination of 26 amino acids does not cause inactivation due to the expected major conformational changes. However, this deletion does modify the substrate specificity of MEK1b and makes it suitable to phosphorylate ERK1c without modifying the unique feature of MEKs, which are very selective kinases to their respective ERKs. Since the C-terminal region, just after the CRS/CD domain, is modified in ERK1c, it is still possible that the interaction between the kinases is mediated by the MEK1b's D-domain (Tanoue et al. 2000). This is supported by the fact that the ERK1c phosphorylation rate by MEK1b is higher than the rate of CRS/CDdeficient ERK1 phosphorylation, and some interactions between MEK1b and ERK1c do exist in coimmunoprecipitation assays (data not shown). Therefore, the changes in interaction of ERK1c and MEK1b are likely to be mediated mainly by the deleted regions, which are consequently identified here to contribute some binding affinity in the ERK1-MEK1 association.

The distinct activation of the two ERK routes raises the question as to what might be the mechanism of their activation. The difference in activation upon EGF stimulation, as compared with nocodazole treatments, may indicate a distinct upstream mechanism of activation of MEK1b and MEK1. Since Raf-1 was reported to participate in mitotic ERK1/2 activation (Colanzi et al. 2003b; Liu et al. 2004), it is possible that MEK1/2 are activated at this stage by this isoform. However, it was shown that the phosphorylation of MEK1 during $\mathrm{G}_{2} / \mathrm{M}$ of the cell cycle is different from that in interphase cells (Colanzi et al. 2000). This effect could be due to a different upstream component that phosphorylates mainly MEK1b, resulting in a distinct phosphorylation pattern. Such a distinct upstream component is likely to be activated only during mitosis and not upon mitogenic stimulation. Since MEK1b effects are inhibited by the general Raf inhibitor Sorafenib (Supplemental Fig. S1), this component might be either A-Raf or an alternatively spliced form of the other Raf kinases that are activated specifically in $\mathrm{G}_{2} / \mathrm{M}$.

ERK1/2 are activated by a wide variety of extracellular agents that induce different, or even opposing, cellular processes. For example, ERK1/2 were shown to induce cell proliferation upon mitogenic stimulation (Seger and Krebs 1995), but at the same time, they can mediate apoptotic signals upon certain proapoptotic stimulations (Bacus et al. 2001). These effects raise the question as to how the specificity of the different signals transmitted by the ERK cascade is regulated. Several mechanisms that participate in this specificity determination have been proposed in the past years (Shaul and Seger 2007); one of them is the presence of several similar isoforms (Lloyd 2006), including alternatively spliced forms (Shaul and Seger 2007) at each tier of the cascade. Such isoforms, which might be differentially regulated and have distinct substrates, may extend the specificity of the signal transmitted by the cascade.

Several alternatively spliced isoforms of components of MAPK cascades have been demonstrated to function differently from their main isoforms. In the p38 cascade, Mxi2 and Exip, which differ from the p38 $\alpha$ in their C terminus (18 amino acids in Mxi2) (Zervos et al. 1995) and 58 amino acids in Exip (Sudo et al. 2002), have unique signaling functions. Mxi2 binds ERK1/2 and regulates their subcellular localization (Casar et al. 2007), while Exip binds Toll-interacting protein and down-regulates the NF-кB pathway (Yagasaki et al. 2004). Since the fulllength $\mathrm{p} 38 \alpha$ is not involved in these processes, Exip and 
Mxi2 extend the number of p38 functions. Different alternatively spliced forms were also reported for ERK5 (Yan et al. 2001), MEK5 (English et al. 1995), JNK (Gupta et al. 1996), MKK7 (Tournier et al. 1999), and others. In addition, besides ERK1c, two alternatively spliced forms-ERK1b (Yung et al. 2000) and ERK2b (Gonzalez et al. 1992/_have been reported for ERKs, and other forms may exist as well (Ben-David et al. 2006). Thus, alternatively spliced isoforms of components of MAPK cascades add to the complexity of the signaling network, which allows the regulation of the wide range of processes governed by these cascades.

The involvement of the ERK cascade in regulating $\mathrm{G}_{2} / \mathrm{M}$ and mitosis phases of the cell cycle is well established (Chambard et al. 2007). In the past few years, the ERK cascade has been implicated in the regulation of several mitotic components, such as CDC25 (Wang et al. 2007), CENP-E (Zecevic et al. 1998), SWI/SNF (Sif et al. 1998), and PLK3 (Xie et al. 2004). In addition, the ERK cascade may play a role in the mitotic Golgi fragmentation (Acharya et al. 1998; Kano et al. 2000; Feinstein and Linstedt 2007). It was also suggested that MEK1 is activated at early stages of mitosis when it is presumably phosphorylated by Raf1 (Colanzi et al. 2000, 2003a). However, the mitotic MEK generated different peptides from the interphase MEK1 upon trypsin digestion (Colanzi et al. 2000). In addition, cleavage of the mitotic MEK with anthrax lethal factor (which cleaves the $\mathrm{N}$ terminus of MEK1 and disrupts its activity) did not affect Golgi fragmentation (Colanzi et al. 2000). Taken together, our results indicate that the MEK that participates in Golgi fragmentation is distinct from $M E K 1 / 2$, and we propose here that it is, in fact, MEK1b. However, our results do not exclude the possibility that MEK1/2 are modified in mitosis differently from their modifications during interphase, and this modification allows them to participate in the fragmentation as well.

In summary, we show here that ERK1c is activated mainly by MEK1b and not by MEK1/2. We propose here that during mitosis, the ERK cascade is divided into two routes, the classic MEK1/2-ERK1/2 and the alternative MEK1b-ERK1c. Both of these pathways are likely to participate in the regulation of $\mathrm{G}_{2} / \mathrm{M}$ and mitosis. However, Golgi fragmentation within this phase seems to be regulated exclusively by the MEK1b-ERK1c route. Therefore, this study provides a new insight into the regulation of the ERK signaling cascade and suggests that the ERK cascade specificity could be achieved by the existence of a cascade of alternatively spliced isoforms, with a distinct mode of regulation and downstream effects.

\section{Materials and methods}

\section{Reagents and antibodies}

Thymidine, nocodazole, MBP, BFA, propidium iodide, EGF, and ATP were purchased from Sigma. Protein A/G PLUS-agarose beads were from Santa Cruz Biotechnologies. Sepharose immobilized protein A, ECL kit, glutathione beads, and $\left[\gamma^{32}\right.$-P]ATP were from GE-Healthcare. 4',6-diamidino-2-phenylindole (DAPI) was from Molecular Probes, and U0126 was from Calbiochem. Sorafenib was provided by Bayer Pharmaceuticals. Anti-p58, phospho-MEK (pMEK), CRS/CD domain of ERK [gERK(CRS)], and diphospho-ERK (pERK) Abs were obtained from Sigma Israel. The anti-phospho-MEK (pMEK) Ab used in most experiments was from Cell Signaling Technology. Anti-gMEK(C-18), antigMEK (H-8), and gERK(C-term) (C-16) Abs were from Santa Cruz Biotechnologies. The anti-ERK1c Ab was prepared by the $\mathrm{Ab}$ unit of the Weizmann Institute of Science as described previously (Aebersold et al. 2004). The anti-GFP Ab was from Roche Diagnostics. The developing substrates NBT and BCIP were from Promega. FITC, rhodamine, alkaline phosphatase, and horseradish peroxidase conjugated secondary Abs were from Jackson ImmunoResearch.

\section{Buffers}

The buffers used were Buffer A $(50 \mathrm{mM} \beta$-glycerophosphate $(\mathrm{pH}$ 7.3), $1.5 \mathrm{mM}$ EGTA, $1 \mathrm{mM}$ EDTA, $1 \mathrm{mM}$ DTT, and $0.1 \mathrm{mM}$ sodium vanadate) and Buffer $\mathrm{B}(1 \mathrm{M} \mathrm{NaCl}$ in Buffer A). Buffer $\mathrm{H}$ was Buffer A supplemented with $1 \mathrm{mM}$ benzamidine, $10 \mu \mathrm{g} / \mathrm{mL}$ aprotinin, $10 \mu \mathrm{g} / \mathrm{mL}$ leupeptin, and $2 \mu \mathrm{g} / \mathrm{mL}$ pepstatin-A. Buffer $\mathrm{RM}$ (reaction mixture at threefold concentration) was $30 \mathrm{mM}$ $\mathrm{MgCl}_{2}, 4.5 \mathrm{mM}$ DTT, 75 mM $\beta$-glycerophosphate (pH 7.3), 0.15 $\mathrm{mM}$ sodium vanadate, $3.75 \mathrm{mM}$ EGTA, $30 \mu \mathrm{M}$ calmidazolium, and $2.5 \mathrm{mg} / \mathrm{mL}$ bovine serum albumin. The radioimmunoprotein assay (RIPA) buffer was $137 \mathrm{mM} \mathrm{NaCl}, 20 \mathrm{mM}$ Tris (pH 7.4), $10 \%$ $(\mathrm{v} / \mathrm{v})$ glycerol, $1 \%$ Triton $\mathrm{X}-100,0.5 \%$ deoxycholate, $0.1 \%(\mathrm{w} / \mathrm{v})$ SDS, $2.0 \mathrm{mM}$ EDTA, $1.0 \mathrm{mM}$ PMSF, and $20 \mu \mathrm{M}$ leupeptin.

\section{DNA constructs and Sh-RNA}

GFP in pEGFP was purchased from Clontech. MEK1 was subcloned into pEGFP-N1 as described previously (Jaaro et al. 1997; Yao et al. 2001), and MEK2 was subcloned into the same vector. MEK1b-GFP was prepared by PCR wherein MEK1-GFP was used as a template, the sense primer was GTAATAAAA GGCCTGACA (517-535 of MEK1), and antisense ATCTGCA TGGAGCACATG (421-438 of MEK1). $\triangle$ N-EE-MEK1-GFP was prepared previously (Burgermeister et al. 2007), and $\triangle$ N-EEMEK1b-GFP was prepared by inserting $\triangle$ N-EE-MEK1b into the BamHI and EcoRI of pEGFP-N1. The HIS- $\Delta$ N-EE-MEK1b (in pRSET) was prepared in a similar way to the preparation of MEK1 (Jaaro et al. 1997). GFP-ERK1c, was prepared in a pEGFP vector, and GST-ERK1c, as well as ERK1 and ERK2, was prepared in pGEX-2T (Aebersold et al. 2004). To generate the Sh-RNA construct pSUPER-MEK1, we chose a MEK1b or MEK1 unique sequence and cloned them into pSUPER (Brummelkamp et al. 2002). For MEK1, the sequence that was used is TGGATCAA GTCCTGAAGAA (base pairs 452-470). For MEK1b, the sequence that was used is ATGGAGCACATGGTAATAA (base pairs 427-445). As described (Shaul and Seger 2006) for ERK1c, the sequence was CGACGGATGAGGTGGGCCA (base pairs 1007-1025). For ERK1, the sequence was AGCTGGATGACCTA CCTAA (base pairs 1052-1070).

\section{Cell culture and transfection}

HeLa and HEK293T cells were grown in Dulbecco's modified Eagle's medium (DMEM) supplemented with $10 \%$ fetal calf serum (FCS; GIBCO). Transfection into the cells was carried out using the polyethylenimine (PEI) method as described (Boussif et al. 1995). Briefly, the cells were grown to $50 \%-70 \%$ confluence in 12-well plates. The plasmid $(1.5 \mu \mathrm{g})$ was suspended in $125 \mu \mathrm{L}$ of PBS and mixed with PEI solution $(5 \mu \mathrm{L}$ of $3 \mathrm{mM}$ PEI in $125 \mathrm{mM} \mathrm{NaCl})$. The mix was left for $15 \mathrm{~min}$ at $23^{\circ} \mathrm{C}$ and then 
incubated with the cells for $90 \mathrm{~min}$, after which the cells were washed and placed in DMEM $+10 \%$ FCS.

\section{Immunofluorescence studies}

Cells were fixed $\left(5 \mathrm{~min}\right.$ methanol at $\left.-20^{\circ} \mathrm{C}\right)$, followed by a 20 min permeabilization/blocking solution $(0.1 \%$ Triton X-100/2\% $\mathrm{BSA})$. The $\mathrm{Ab}$ of choice was added for $1 \mathrm{~h}$, then washed out and incubated with fluorescence-tagged (Cy2, FITC, or rhodamine) secondary Abs for $1 \mathrm{~h}\left(\right.$ all at $\left.23^{\circ} \mathrm{C}\right)$. Nuclei were stained with 0.1 $\mathrm{mg} / \mathrm{mL}$ DAPI in PBS. The slides were visualized using fluorescence microscope (Optiphot; Nikon) with $40 \times / 0.7$ objectives. Digital images of cells were captured using a DVC camera and C-view V2.1 DVC Imaging software. Image processing was done using Photoshop 7.0 (Adobe Systems).

\section{Preparation of cell extracts and Western blotting}

After treatment, the cells were rinsed twice with ice-cold PBS and scraped into RIPA buffer ( $0.5 \mathrm{~mL}$ per plate). The extracts were centrifuged $\left(20,000 \mathrm{~g}, 15 \mathrm{~min}, 4^{\circ} \mathrm{C}\right)$, and the supernatants were further kept at $4^{\circ} \mathrm{C}$. The supernatants were then separated by a $12 \%$ SDS-PAGE, transferred onto a nitrocellulose membrane, and probed with the appropriate $\mathrm{Ab}$ as described (Shaul and Seger 2006).

\section{Immunoprecipitation}

Cell extracts prepared as described above were incubated $(2 \mathrm{~h}$, $4^{\circ} \mathrm{C}$ ) with anti-ERK1c (affinity-purified) bound to protein ASepharose, or anti-ERK1 (C-term) or GFP Abs coupled to protein A/G-agarose. For determination of the kinase activity, the beads were washed twice with $0.5 \mathrm{M} \mathrm{LiCl}$ in $0.1 \mathrm{M}$ Tris $(\mathrm{pH} \mathrm{8.0)}$ and once with $1 \mathrm{~mL}$ of Buffer A. Precipitates were taken either to Western blotting or to phosphorylation as below.

\section{In vitro phosphorylation}

Immunoprecipitated, active MEKs attached to beads (15 $\mu \mathrm{L})$, recombinant 6 His- $\Delta$ N-EE-MEK1, as well as $\Delta$ N-EE-MEK1b-HIS (0.5 $\mu$ g per reaction), or Mono-Q fractionated MEK1/MEK1b $(16 \mu \mathrm{L})$ were mixed with either recombinant GST-ERK1c, GSTERK1, or GST-ERK2 (0.5 $\mu \mathrm{g}$ per reaction). Similarly, immunoprecipitated ERK1/2 attached to beads $(15 \mu \mathrm{L})$ were used as kinases to phosphorylate MBP (8 $\mu$ g per reaction). Then, Buffer RM containing $100 \mu \mathrm{M}\left[\gamma^{-32} \mathrm{P}\right]$ ATP $(4000 \mathrm{cpm} / \mathrm{pmol})$ was added to the reaction in a final volume of $30 \mu \mathrm{L}$ and incubated for 20 $\min$ at $30^{\circ} \mathrm{C}$. The reaction was terminated by adding $10 \mu \mathrm{L}$ of $4 \mathrm{xSB}$, and the phosphorylated proteins were resolved on SDSPAGE and subjected to autoradiography and Western blotting with the proper Abs.

\section{Anion exchange chromatography}

Chromatographic separations were carried out at $4^{\circ} \mathrm{C}$ using the Pharmacia FPLC system with a Mono-Q HR5/5 column. Thus, cytosplasmic extracts $(\sim 10 \mathrm{mg}$ of protein, representing cells from 10 culture plates; $10 \mathrm{~cm}$ ) were loaded on a Mono-Q column equilibrated with Buffer A (1 mL/min), and after $12-\mathrm{mL}$ washing with Buffer A, were eluted with $70 \mathrm{~mL}$ of gradient from 0 to $0.4 \mathrm{M}$ $\mathrm{NaCl}$ (in Buffer A; $1 \mathrm{~mL} / \mathrm{min}$ ) and additional $6 \mathrm{~mL}$ of gradient from 0.4 to $1 \mathrm{M} \mathrm{NaCl}$ (Buffer B). Column fractions of $1 \mathrm{~mL}$ were collected in polyethylene tubes and stored at $4{ }^{\circ} \mathrm{C}$, retaining activity of at least $2 \mathrm{wk}$.

\section{Cell synchronization and FACS analysis}

Cells were synchronized at the $\mathrm{G}_{1} / \mathrm{S}$ boundary by the doublethymidine block (Merrill 1998). In short, HeLa cells were treated with $2 \mathrm{mM}$ thymidine, washed twice with PBS, grown for $8 \mathrm{~h}$ in DMEM $/ 10 \%$ FCS, and then treated again with $2 \mathrm{mM}$ thymidine for $16 \mathrm{~h}$ and washed again with PBS. This marks time 0, after which the cells were grown under the regular conditions for the indicated times. For FACS analysis, HeLa cells were trypsinized, washed with PBS, and fixed in $70 \%$ ice-cold methanol for at least $1 \mathrm{~h}$. The samples were then spun down $(500 \mathrm{~g}, 2 \mathrm{~min})$ and resuspended in $0.5 \mathrm{~mL}$ of staining solution $(0.001 \%$ Triton X-100, $0.1 \mathrm{mM}$ EDTA, $100 \mu \mathrm{g} / \mathrm{mL}$ RNase, $50 \mu \mathrm{g} / \mathrm{mL}$ propidium iodide in PBS). The cells were analyzed by FACsort (Becton Dickinson), and the percentage of cells was calculated using the CellQuest software. HeLa cells were also synchronized at the M phase using $100 \mathrm{ng} / \mathrm{mL}$ nocodazole for $24 \mathrm{~h}$ (Merrill 1998).

\section{Acknowledgments}

We thank Ms. Tamar Hanoch for her technical help, Ms. Martie Spiegel for proofreading the manuscript, and Professor Vivek Malhotra for helpful discussions. This work was supported by a grant from the Binational Science foundation (BSF) USA-Israel. R.S. is an Incumbent of the Yale S. Lewine and Ella Miller Lewine professorial chair for cancer research.

\section{References}

Acharya U, Mallabiabarrena A, Acharya JK, Malhotra V. 1998. Signaling via mitogen-activated protein kinase kinase (MEK1) is required for Golgi fragmentation during mitosis. Cell 92: 183-192.

Aebersold DM, Shaul YD, Yung Y, Yarom N, Yao Z, Hanoch T, Seger R. 2004. Extracellular signal-regulated kinase 1c (ERK1c), a novel 42-kilodalton ERK, demonstrates unique modes of regulation, localization, and function. Mol Cell Biol 24: 10000-10015.

Alessi DR, Saito Y, Campbell DG, Cohen P, Sithanandam G, Rapp U, Ashworth A, Marshall CJ, Cowley S. 1994. Identification of the sites in MAP kinase kinase-1 phosphorylated by p74raf-1. EMBO J 13: 1610-1619.

Bacus SS, Gudkov AV, Lowe M, Lyass L, Yung Y, Komarov AP, Keyomarsi K, Yarden Y, Seger R. 2001. Taxol-induced apoptosis depends on MAP kinase pathways (ERK and p38) and is independent of p53. Oncogene 20: 147-155.

Ben-David H, Aruna BV, Seger R, Sela M, Mozes E. 2006. A 50$\mathrm{kDa}$ ERK-like protein is up-regulated by a dual altered peptide ligand that suppresses myasthenia gravis-associated responses. Proc Natl Acad Sci 103: 18232-18237.

Bendetz-Nezer S, Seger R 2005. Mek1. UCSD-Nature Molecule Pages doi: 10.1038/mp.a001505.01.

Boussif, O, Lezoualc'h, F, Zanta, MA, Mergny, MD, Scherman, D, Demeneix, B, and Behr, JP 1995. A versatile vector for gene and oligonucleotide transfer into cells in culture and in vivo: Polyethylenimine. Proc Natl Acad Sci 92: 7297-7301.

Brummelkamp TR, Bernards R, Agami R. 2002. A system for stable expression of short interfering RNAs in mammalian cells. Science 296: 550-553.

Burgermeister E, Chuderland D, Hanoch T, Meyer M, Liscovitch M, Seger R. 2007. Interaction with MEK causes nuclear export and downregulation of peroxisome proliferator-activated receptor $\gamma$. Mol Cell Biol 27: 803-817.

Casar B, Sanz-Moreno V, Yazicioglu MN, Rodriguez J, Berciano MT, Lafarga M, Cobb MH, Crespo P. 2007. Mxi2 promotes 
stimulus-independent ERK nuclear translocation. EMBO $J$ 26: 635-646.

Cha H, Shapiro P. 2001. Tyrosine-phosphorylated extracellular signal-regulated kinase associates with the Golgi complex during $\mathrm{G}_{2} / \mathrm{M}$ phase of the cell cycle: Evidence for regulation of Golgi structure. J Cell Biol 153: 1355-1367.

Cha H, Hancock C, Dangi S, Maiguel D, Carrier F, Shapiro P. 2004. Phosphorylation regulates nucleophosmin targeting to the centrosome during mitosis as detected by cross-reactive phosphorylation-specific MKK1/MKK2 antibodies. Biochem J 378: 857-865.

Chambard JC, Lefloch R, Pouyssegur J, Lenormand P. 2007. ERK implication in cell cycle regulation. Biochim Biophys Acta 1773: $1299-1310$.

Chardin P, McCormick F. 1999. Brefeldin A: The advantage of being uncompetitive. Cell 97: 153-155.

Colanzi A, Deerinck TJ, Ellisman MH, Malhotra V. 2000. A specific activation of the mitogen-activated protein kinase kinase 1 (MEK1) is required for Golgi fragmentation during mitosis. J Cell Biol 149: 331-339.

Colanzi A, Suetterlin C, Malhotra V. 2003a. Cell-cycle-specific Golgi fragmentation: How and why? Curr Opin Cell Biol 15: 462-467.

Colanzi A, Sutterlin C, Malhotra V. 2003b. RAF1-activated MEK1 is found on the Golgi apparatus in late prophase and is required for Golgi complex fragmentation in mitosis. J Cell Biol 161: 27-32.

English JM, Vanderbilt CA, Xu S, Marcus S, Cobb MH. 1995. Isolation of MEK5 and differential expression of alternatively spliced forms. J Biol Chem 270: 28897-28902.

Feinstein TN, Linstedt AD. 2007. Mitogen-activated protein kinase kinase 1-dependent Golgi unlinking occurs in $\mathrm{G}_{2}$ phase and promotes the $\mathrm{G}_{2} / \mathrm{M}$ cell cycle transition. Mol Biol Cell 18: 594-604.

Gonzalez FA, Raden DL, Rigby MR, Davis RJ. 1992. Heterogeneous expression of four MAP kinase isoforms in human tissues. FEBS Lett 304: 170-178.

Gupta S, Barrett T, Whitmarsh AJ, Cavanagh J, Sluss HK, Derijard B, Davis RJ. 1996. Selective interaction of JNK protein kinase isoforms with transcription factors. EMBO $J$ 15: 2760-2770.

Hendricks LC, Gabel CA, Suh K, Farquhar MG. 1991. A 58-kDa resident protein of the cis Golgi cisterna is not terminally glycosylated. J Biol Chem 266: 17559-17565.

Jaaro H, Rubinfeld H, Hanoch T, Seger R. 1997. Nuclear translocation of mitogen-activated protein kinase kinase (MEK1) in response to mitogenic stimulation. Proc Natl Acad Sci 94: 3742-3747.

Kano F, Takenaka K, Yamamoto A, Nagayama K, Nishida E, Murata M. 2000. MEK and cdc2 kinase are sequentially required for golgi disassembly in MDCK cells by the mitotic Xenopus extracts. I Cell Biol 149: 357-368.

Liu X, Yan S, Zhou T, Terada Y, Erikson RL. 2004. The MAP kinase pathway is required for entry into mitosis and cell survival. Oncogene 23: 763-776.

Lloyd A. 2006. Distinct functions for ERKs? J Biol 5: 13.1-13.4. doi: $10.1186 /$ jbiol46.

Mansour SJ, Candia JM, Gloor KK, Ahn NG. 1996. Constitutively active mitogen-activated protein kinase kinase 1 (MAPKK1) and MAPKK2 mediate similar transcriptional and morphological responses. Cell Growth Differ 7: 243-250.

Merrill GF. 1998. Cell synchronization. Methods Cell Biol 57: 229-249.

Ohren JF, Chen H, Pavlovsky A, Whitehead C, Zhang E, Kuffa P, Yan C, McConnell P, Spessard C, Banotai C, et al. 2004. Structures of human MAP kinase kinase 1 (MEK1) and MEK2 describe novel noncompetitive kinase inhibition. Nat Struct Mol Biol 11: 1192-1197.

Seger R, Krebs EG. 1995. The MAPK signaling cascade. FASEB J 9: 726-735.

Seger R, Seger D, Lozeman FJ, Ahn NG, Graves LM, Campbell JS, Ericsson L, Harrylock M, Jensen AM, Krebs EG. 1992. Human T-cell MAP kinase kinases are related to yeast signal transduction kinases. J Biol Chem 267: 25628-25631.

Shaul YD, Seger R. 2006. ERK1c regulates Golgi fragmentation during mitosis. J Cell Biol 172: 885-897.

Shaul YD, Seger R. 2007. The MEK/ERK cascade: From signaling specificity to diverse functions. Biochim Biophys Acta 1773: 1213-1226.

Sif S, Stukenberg PT, Kirschner MW, Kingston RE. 1998. Mitotic inactivation of a human SWI/SNF chromatin remodeling complex. Genes \& Dev 12: 2842-2851.

Sudo T, Yagasaki Y, Hama H, Watanabe N, Osada H. 2002. Exip, a new alternative splicing variant of $\mathrm{p} 38 \alpha$, can induce an earlier onset of apoptosis in HeLa cells. Biochem Biophys Res Commun 291: 838-843.

Takenaka K, Moriguchi T, Nishida E. 1998. Activation of the protein kinase p38 in the spindle assembly checkpoint and mitotic arrest. Science 280: 599-602.

Tanoue T, Adachi M, Moriguchi T, Nishida E. 2000. A conserved docking motif in MAP kinases common to substrates, activators and regulators. Nat Cell Biol 2: 110-116.

Tournier C, Whitmarsh AJ, Cavanagh J, Barrett T, Davis RJ. 1999. The MKK7 gene encodes a group of c-Jun NH2terminal kinase kinases. Mol Cell Biol 19: 1569-1581.

Wang R, He G, Nelman-Gonzalez M, Ashorn CL, Gallick GE, Stukenberg PT, Kirschner MW, Kuang J. 2007. Regulation of Cdc25C by ERK-MAP kinases during the $\mathrm{G}_{2} / \mathrm{M}$ transition. Cell 128: 1119-1132.

Wellbrock C, Karasarides M, Marais R. 2004. The RAF proteins take centre stage. Nat Rev Mol Cell Biol 5: 875-885.

Xie S, Wang Q, Ruan Q, Liu T, Jhanwar-Uniyal M, Guan K, Dai W. 2004. MEK1-induced Golgi dynamics during cell cycle progression is partly mediated by Polo-like kinase-3. Oncogene 23: 3822-3829.

Yagasaki Y, Sudo T, Osada H. 2004. Exip, a splicing variant of p38 $\alpha$, participates in interleukin-1 receptor proximal complex and downregulates NF-кB pathway. FEBS Lett 575: 136140.

Yan C, Luo H, Lee JD, Abe J, Berk BC. 2001. Molecular cloning of mouse ERK5/BMK1 splice variants and characterization of ERK5 functional domains. J Biol Chem 276: 10870-10878.

Yao Z, Flash I, Raviv Z, Yung Y, Asscher Y, Pleban S, Seger R. 2001. Non-regulated and stimulated mechanisms cooperate in the nuclear accumulation of MEK1. Oncogene 20: 7588-7596.

Yung Y, Dolginov Y, Yao Z, Rubinfeld H, Michael D, Hanoch T, Roubini E, Lando Z, Zharhary D, Seger R. 1997. Detection of ERK activation by a novel monoclonal antibody. FEBS Lett 408: 292-296.

Yung Y, Yao Z, Hanoch T, Seger R. 2000. ERK1b, a 46-kDa ERK isoform that is differentially regulated by MEK. I Biol Chem 275: 15799-15808.

Zecevic M, Catling AD, Eblen ST, Renzi L, Hittle JC, Yen TJ, Gorbsky GJ, Weber MJ. 1998. Active MAP kinase in mitosis: Localization at kinetochores and association with the motor protein CENP-E. J Cell Biol 142: 1547-1558.

Zervos AS, Faccio L, Gatto JP, Kyriakis JM, Brent R. 1995. Mxi2, a mitogen-activated protein kinase that recognizes and phosphorylates Max protein. Proc Natl Acad Sci 92: 10531-10534.

Zheng CF, Guan KL. 1993. Properties of MEKs, the kinases that phosphorylate and activate the extracellular signal-regulated kinases. J Biol Chem 268: 23933-23939. 


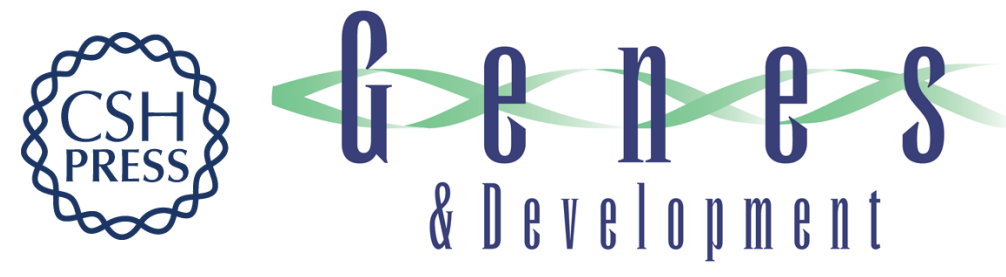

\section{Specific phosphorylation and activation of ERK1c by MEK1b: a unique route in the ERK cascade}

Yoav D. Shaul, Gilad Gibor, Alexander Plotnikov, et al.

Genes Dev. 2009, 23:

Access the most recent version at doi:10.1101/gad.523909

Supplemental http://genesdev.cshlp.org/content/suppl/2009/07/09/23.15.1779.DC1
Material

References This article cites 49 articles, 24 of which can be accessed free at: http://genesdev.cshlp.org/content/23/15/1779.full.html\#ref-list-1

License

Email Alerting Receive free email alerts when new articles cite this article - sign up in the box at the top Service right corner of the article or click here.

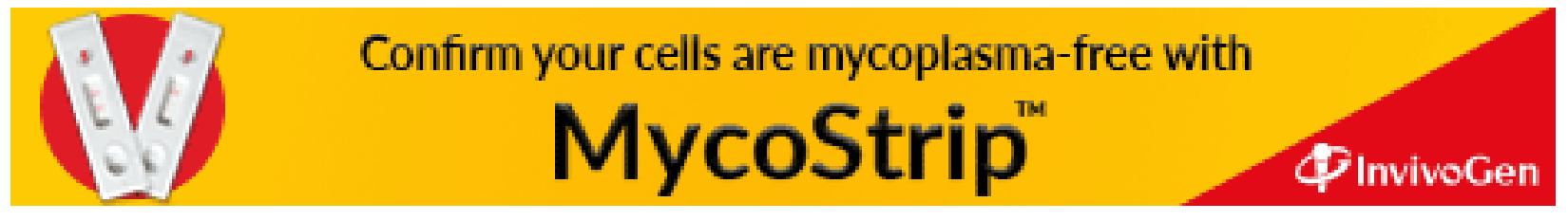

